\title{
FOLDING THEORY OF IMPLICATIVE AND OBSTINATE IDEALS IN BL-ALGEBRAS
}

\author{
AKBAR PAAD \\ Department of Mathematics \\ University of Bojnord, Bojnord, Iran \\ e-mail: akbar.paad@gmail.com
}

\begin{abstract}
In this paper, the concepts of $n$-fold implicative ideals and $n$-fold obstinate ideals in $B L$-algebras are introduced. With respect to this concepts, some related results are given. In particular, it is proved that an ideal is an $n$-fold implicative ideal if and only if is an $n$-fold Boolean ideal. Also, it is shown that a $B L$-algebra is an $n$-fold integral $B L$-algebra if and only if trivial ideal $\{0\}$ is an $n$-fold obstinate ideal. Moreover, the relation between $n$-fold obstinate ideals and $n$-fold (integral) obstinate filters in $B L$-algebras are studied by using the set of complement elements. Finally, it is proved that ideal $I$ of $B L$-algebra $L$ is an $n$-fold obstinate ideal if and only if $\frac{L}{I}$ is an $n$-fold obstinate $B L$-algebra.
\end{abstract}

Keywords: $B L$-algebra, ideal, $n$-fold implicative ideal, $n$-fold obstinate ideal.

2010 Mathematics Subject Classification: 03G25, 03G05, 06D35, 06E99.

\section{REFERENCES}

[1] C.C. Chang, Algebraic analysis of many valued logics, Trans. Amer. Math. Soc. 88 (1958) 467-490. doi:10.1090/S0002-9947-1958-0094302-9

[2] A. Di Nola, G. Georgescu and A. Iorgulescu, Pseduo BL-algebras Part I, Mult. Val. Logic, 8 (2002) 673-714.

[3] A. Di Nola and L. Leustean, Compact representations of BL-algebras, Department of Computer Science, University Aarhus. BRICS Report Series, (2002).

[4] M. Haveshki and E. Eslami, n-Fold filters in BL-algebras, Math. Log. Quart. 54 (2008) 178-186.

[5] S. Motamed and A.B. Saeid, n-Fold obstinate filters in BL-algebras, Neural. Comput. Applic. 20 (2011) 461-472. 
[6] C. Lele and J.B. Nganou, $M V$-algebras derived from ideals in BL-algebras, Fuzzy Sets and Systems 218 (2013) 103-113.

[7] P. Hájek, Metamathematics of Fuzzy Logic, Trends in Logic 4 (Kluwer Academic Publishers, 1998), ISBN:9781402003707.

[8] A. Paad, Integral ideals and maximal ideals in BL-algebras, An.Univ. Craiova Ser. Mat. Inform. 43 (2016) 231-242.

[9] A. Paad, n-Fold integral ideals and n-fold Boolean ideals in BL-algebras, Afr. Mat. 28 (2017) 971-984.

[10] A. Paad and R.A. Borzooei, Generalization of integral filters in BL-algebras and n-fold integral BL-algebras, Afr. Mat. 26 (2015) 1299-1311.

[11] Y. Yang and X. Xin, On characterization of BL-algebras via implicative ideals, Italian J. Pure and Appl. Math. 37 (2017) 493-506.

[12] E. Turunen, Boolean deductive systems of BL-algebras, Arch. Math. Logic. 40 (2001) $467-473$.

Received 5 July 2018

Revised 3 September 2018

Accepted 8 September 2018 